\title{
Sosialisasi Sistem Informasi Persediaan Barang Pada PT. Immunotec Profarmasia
}

\author{
Wilda Rina Hasibuan ${ }^{1 *}$, Joko Susilo ${ }^{2}$, Supardi ${ }^{3}$, Mahardika Abdi Prawira ${ }^{4}$, Suardi $^{5}$ \\ 1,2,3,4Jurusan/Program Studi Teknik Informatika, Fakultas Teknik \\ ${ }^{5}$ Jurusan/Program Studi Teknik Mesin, Fakultas Teknik \\ 1,2,3,4,5Sekolah Tinggi Teknologi Sinar Husni, Jl. Veteran Gg. Utama Psr V. Helvetia Medan \\ Deli Serdang, Sumatera Utara 20373 \\ *email: wildarinahasibuan77@gmail.com
}

Informasi Artikel

Diterima Redaksi: 9 Desember 2021

Revisi Akhir: 29 Januari 2022

Diterbitkan Online: 15 Januari 2022

Kata Kunci:

Pelatihan SIM, Persediaan Barang

\section{PENDAHULUAN}

PT. Immunotec Profarmasia Impro Best PRO adalah salah satu perusahaan yang bergerak dalam bidang penjualan Suplemen Food. Salah Satu cabang dari PT. Immunotec Profarmasia yang dikenal dengan nama Impro Best PRO yang berada di Taman Rafles Jl. Ampera Raya No. 1-G Glugur Darat Medan Timur Kode Pos 20238. Best PRO International adalah sebuah perusahaan dengan penjualan langsung atau sistem Direct Selling. Best PRO International didirikan pada tahun 1998 oleh Mr. Thomas Hosean Ciovanlee. adalah pengusaha nasional pemilik berbagai unit usaha. Kemampuan dalam berbisnis dan melihat peluang patut dibanggakan. Pada tahun 1998 pada saat itu bangsa Indonesia sedang mengahadapi krisis moneter tetapi Mr. Thomas berhasil
Abstrak

Pengelolaan data dengan menggunakan teknologi komputer yang semakin maju seiring dengan perkembangan hardware dan software sudah pasti akan mempermudah dalam pengolahan data penjualan dan pembelian serta persediaan barang. Sistem Persediaan barang pada PT. Immunotec Profarmasia Impro Best PRO masih manual dan belum terintegrasi dengan baik. Penanganan dengan sistem manual sering terjadi kendala seperti terjadinya kesalahan dalam pengecekan stok barang sehingga laporan menjadi redudansi data yang mengakibatkan proses pencarian data stok barang membutuhkan waktu yang lama. Dibangunnya sistem informasi ini diharapkan dapat membantu PT. Immunotec Profarmasia Impro Besr PRO dalam mengelola data persediaan barang yang diperoleh dari pembelian dan penjualan. Dalam pembuatan sistem informasi persediaan menggunakan bahasa pemrograman visual Basic 2008 dan SQL Server sebagai databasenya. Aplikasi sistem informasi persediaan barang diharapkan dapat memonitoring stok barang yang masuk maupung barang yang keluar agar mampu meningkatkan efektifitas dan efisiensi perusahaan.Penerapan sistem informasi nantinya dapat memaksimalkan kinerja para pegawai sehingga mendapatkan hasil yang lebih baik dan pemrosesan data menjadi lebih cepat.

meyakinkan Immunotec Research Inc.Canada untuk bekerjasama dalam pemasaran produk-produk unggulannya di Indonesia melalui Best PRO International. Best PRO International tergabung dalam Roxy Group (apotek Roxy, rumah sakit, pabrik herbal, laboratorium herbal, restoran dan perusahaan direct selling). Saat ini Best PRO International menjadi perusahaan satusatunya di Indonesia yang memegang lisensi "partnership" dengan Immunotec Inc. Canada. Takhan yaitu, Best PRO International juga menjadi perusahaan satusatunya di Indonesia yang memegang lisensi "partnership" dengan Mineral Resources International (MRI) sebagai Distributor No.1 produk Concentrated Mineral di Indonesia. Hingga kini Best PRO International terus bertumbuh dan berkembang ke seluruh pelosok Nusantara 
dengan jumlah member, mobile stockist, sub centre dan centre yang semakin hari semakin meningkat pesat dan mencakup hampir ke seluruh kalangan masyarakat. Sumber Daya Manusia yang handal, professional dan berdedikasi tinggi, akan selalu berkomitmen dalam melayani seluruh mitra kerja yang ada di seluruh Indonesia. Sistem administrasi yang tertatarapi akan memberikan kemudahan tersendiri bagi mitra kerja Best PRO International dalam

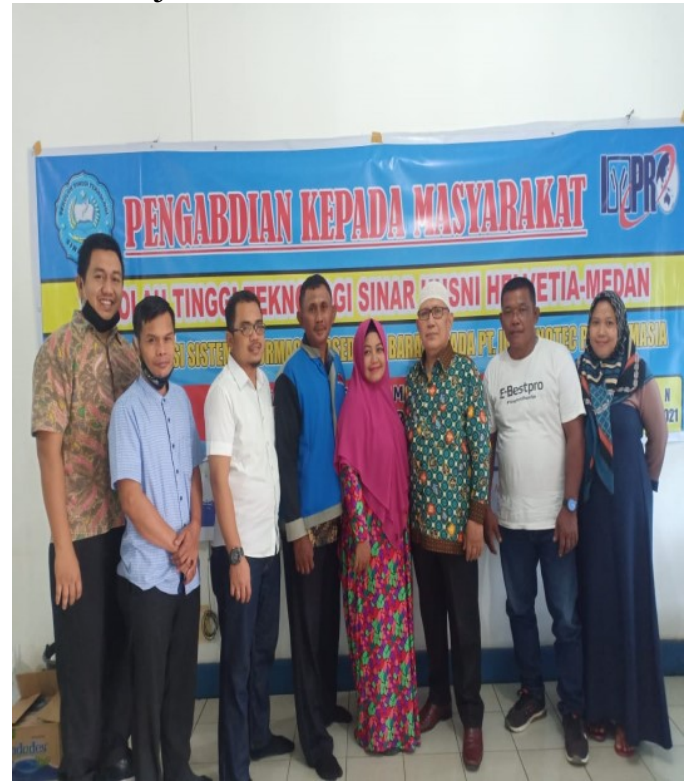

Gambar 1. Foto Bersama Pegawai PT. Immunotec Profarmasia Impro Best PRO Biasanya untuk menyediakan jumlah suplemen food yang akan dijual, PT. Immunotec Profarmasia Impro Best PRO menyesuaikannya dengan permintaan konsumen ataupun permintaan pasar dengan melihat data-data hasil penjualan setiap bulannya. Sistem inventory (persediaan) masih dilakukan secara manual sehingga sulit mengetahui persediaan barang pada PT. Immunotec Profarmasia Impro Best PRO. Hal ini sangat berpengaruh terhadap kemajuan dalam memperoleh hasil yang memuaskan serta keuntungan yang besar. Barang dari bagian sales ke gudang masih dilakukan dengan cara manual (Sarwindah, 2016), yaitu dengan membuat surat permintaan barang keluar. Pencarian stok barang membutuhkan waktu yang lama karena belum adanya sistem persediaan yang dibuat menggunakan aplikasi komputer. Informasi sistem persediaan barang ini sangatlah penting karena proses pembelian dan penjualan dapat diketahui dari data yang ada pada sistem. Sistem ini menyusun strategi bisnis secara cepat, tepat dan akurat. Dengan mengusung Motto " Towards a Healthier Life", Best PRO International berkomitmen mewujudkan hidup yang jauh lebih sehat dan sejahtera bagi masyarakat Indonesia. Kegiatan Pengabdian Masyarakat yang dilakukan pada tanggal 29 September 2021 di Impro Best PRO dengan judul "Sosialisasi Sistem Informasi Persediaan Barang pada PT. Immunotec Profarmasia".

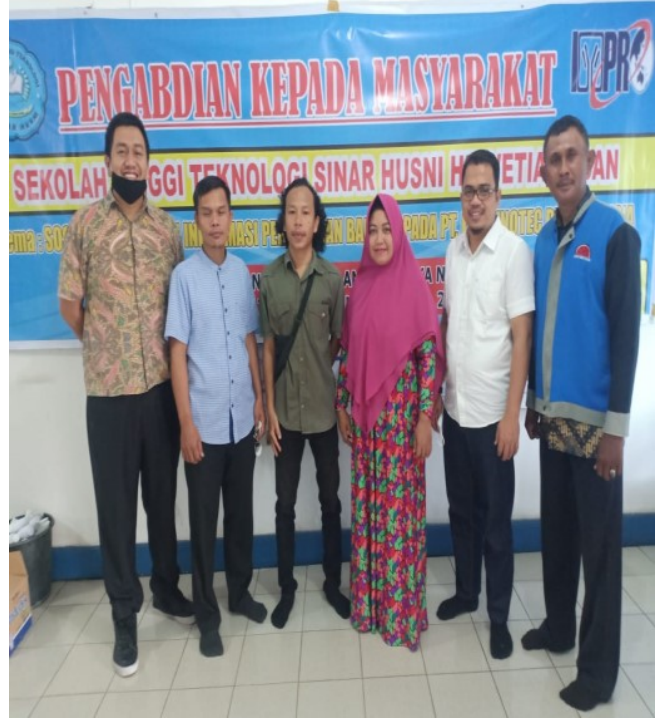

Gambar 2. Foto Bersama Mahasiswa STT Sinar Husni

berbasis komputer yang dapat mengolah data penjualan secara keseluruhan agar dapat meminimalisir kesalahan yang sering timbul. Selain itu sistem ini dapat menyimpan data dengan baik sehingga dapat dengan cepat melihat data - data penjualan setiap bulannya. Pembuatan aplikasi ini menggunakan bahasa pemrograman Visual Basic 2010 dan menggunakan database SQL Server 2008. Implementasi berupa hasil akhir yang dicapai yaitu terbentuknya suatu sistem informasi berbasis Web yang dikoneksikan dengan database server yang memudahkan pengelolaan data dan menghasilkan informasi sebagai penunjang keputusan user (Rahayu et al, 2014). Bentuk pelatihan yang diberikan berupa aplikasi yang diproduksi dari Microsoft yang lebih user friendly dan memberikan manfaat yang begitu banyak dan telah terbukti kebermanfaatannya serperti dalam hal hasil belajar untuk promosi (Maryatun, 2015). Dengan demikian kegiatan pelatihan berguna dalam 
hal peningkatan pengetahuan dan keterampilan (Kurniawansyah, 2018). Diharapkan dengan adanya aplikasi sistem persediaan barang pada PT. Immunotec Profarmasia Impro Best PRO dapat memonitoring barang masuk dan barang keluar sehingga dapat meningkatkan efektifitas dan efisiensi perusahaan. Persediaan barang merupakan salah satu aktivitas kerja yang penting bagi perusahaan dagang, karena persediaan barang merupakan unsur utama dalam bidang perdagangan. Kesalahan kecil mengenai persediaan barang akan mengakibatkan masalah yang fatal, baik itu penumpukan di gudang maupun kekosongan barang. Perusahaan membutuhkan dukungan teknologi berupa sistem informasi yang dapat mempermudah dan mempercepat dalam memberikan informasi mengenai keadaan persediaan barang (S. Susilawati, 2018). Dengan demikian penelitan ini mampu meningkatkan efisiensi dan efektifitas dalam persediaan barang pada perusahaan/lembaga terkait. (Minarni and Susanti, 2014).

\section{METODE}

Kegiatan Pengabdian Kepada Masyarakat yang diadakan pada PTImmunotec Promarsia Impro Best PRO berkaitan dengan pembuatan sistem informasi penjualan barang yang dapat dipergunakan untuk membantu staf dalam melakukan proses penjualan dan pembelian barang. Metode yang digunakan pada pengabdian ini adalah metode penyuluhan/ceramah. Metode ini dilaksanakan dengan memberikan penyuluhan sharing dan diskusi tentang sistem informasi yang nantinya dapat mengatasi masalah pada data persediaan barang yang meliputi transaksi penjualan dan pembelian barang. Sistem informasi ini diharapkan dapat mengurangi human error pada saat pembuatan laporan persediaan dan membangun manajemen dokumen yang baik serta mempermudah customer dalam mendapatkatkan informasi persediaan barang dengan cepat dan tepat. "Sistem informasi adalah kumpulan dari sub-sub sistem yang saling terintegrasi dan berkolaborasi untuk menyelesaikan masalah tertentu dengan cara mengolah data dengan alat yang namanya komputer sehinga memiliki nilai tambah dan bermanfaat bagi pengguna" (Y. Arisandy, dkk). Penyampaian materi berikutnya adalah dengan memberikan pelatihan sistem persediaan barang untuk menciptakan profesionalisme dalam penggunaan sistem. Aplikasi sistem informasi persediaan barang juga dilengkapi dengan program sistem yang dapat memonitoring stok barang sehingga barang yang masuk dan barang yang keluar dapat diketahui dengan jelas. Dengan demikian dihasilkan suatu aplikasi yang dapat meningkatkan efisiensi dan efektifitas dalam persediaan barang pada PT. Immunotec Profarmasia.

Pelatihan dilaksanakan dengan mengajak langsung pegawai menggunakan sistem agar dapat memproses data dengan cepat dan tepat serta memaksimalkan kinerja para pegawai. Evaluasi yang dilakukan dengan melihat implementasi dari pengetahuan yang diberikan selama kegiatan dengan menggunakan Analisa TELOS (Technical, Economic, Legal, Operational, Schedule). Adapun penjelasan dari TELOS adalah :

Technical: Dapat menunjukkan apakah sistem yang diusulkan dapat diterapkan dan untuk selanjutnya dapat dikembangkan dengan menggunakan teknologi yang ada ataupun menggunakan teknologi yang baru. Sistem informasi persediaan baran gini adalah sebuah sistem berbasis desktop yang dapat membantu pada proses transaksi pembelian, transaksi penjualan sehingga membutuhkan personal komputer serta jaringan komputer yang baik.

Economic: Dapat menunjukkan adanya dana yang memadai atau tersedia untuk mendukung dari sistem yang diusulkan. Pada penerapan sistem persediaan barang ini biaya yang dibutuhkan untuk pengadaan barang seperti komputer, hardware dan software.

Legal: Dapat menunjukkan apakah adanya konflik antara sistem dengan kemampuan perusahaan.

Operational: Dapat menunjukkan apakah prosedur dan ketrampilan sumberdaya manusia yang ada dapat mengoperasikan 
sistem persediaan barang atau perlunya prosedur dan tambahan pengetahuan/ketrampilan. Sistem persediaan barang yang dibangun hanya digunakan untuk pengguna lokal pada perusahaan sehingga lebih mudah dioperasikan dan tidak rumit karena sistem persediaan barang dibangun secara sederhana dan dapat dioperasikan oleh beberapa orang, tetapi tetap harus melalui proses pelatihan untuk mengoperasikan sistem tersebut.

Schedule: Sistem yang diusulkan harus dapat berlaku pada suatu kerangka waktu yang bersifat logis. Sistem harus dapat diterapkan dengan melihat faktor kesalahan dalam pembuatan sistem informasi. Semakin sedikit kesalahan yang dibuat maka akan semakin mudah di dalam penerapannya.

\section{HASIL DAN PEMBAHASAN}

Pada hasil dan pembahasan ini akan menjelaskan dari pelaksaan kegiatan sosialisasi yang telah dilakukan dengan member ceramah, penyajian materi dan pelatihan penggunaan sistem informasi.Pada tahap awal dilakukan koordinasi antara Tim Pengabdian Kepada Masyarakat dengan PT. Immunotec Profarmasia untuk mendapatkan solusi dari permasalahan yang dihadapi selama ini dan pihak - pihak yang dilibatkan pada kegiatan pengabdian. Sistem informasi yang dibangun untuk pengguna lokal yang dioperasikan oleh beberapa orang. Estimasi pengabdian masyarakat dilakukan \pm 1 bulan. Ada beberapa tahap dalam proses pembuatan sistem diantaranya:

Desain: Pada tahap desain, dibuat gambaran konsep perancangan database, alur proses pada sistem yang akan dibangun serta user interface. Proses desain akan menerjemahkan syarat kebutuhan sebuah perancangan perangkat lunak yang dapat diperkirakan sebelum dibuat kode program.

Kode Program: Pada tahap ini untuk pembuatan sistem dan diimplementasikan ke dalam kode program maka digunakan bahasa pemrograman Visual Basic 2008 dan menggunakan database SQL Server 2008.
Uji Coba: Pengujian dilakukan dengan menggunakan aplikasi yang telah dibuat yaitu aplikasi sistem persediaan barang.

Hasil: Pada tahap ini program akan diterapkan untuk melakukan persediaan barang.

Rancangan Sistem Yang Akan Dibahas Pada bab ini akan dibahas tentang rancangan sistem yang akan dibahas.

Data Flow Diagram Form Barang. Gambar 3. merupakan Data Flow Diagram Form Penjualan dari Aplikasi Sistem

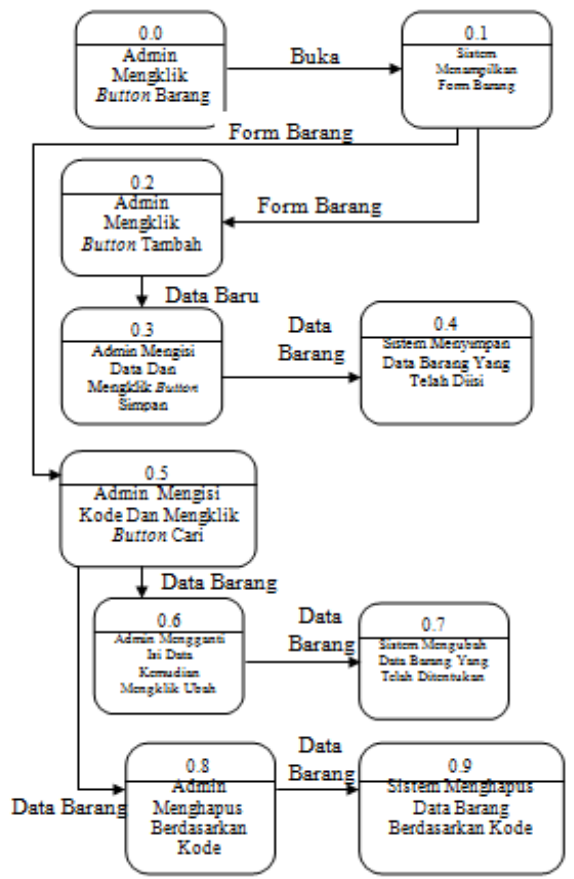

Gambar 3. Data Flow Diagram Form Penjualan 
Gambar 4. merupakan Data Flow Diagram Form Penjualan dari Aplikasi Sistem Persediaan Barang.

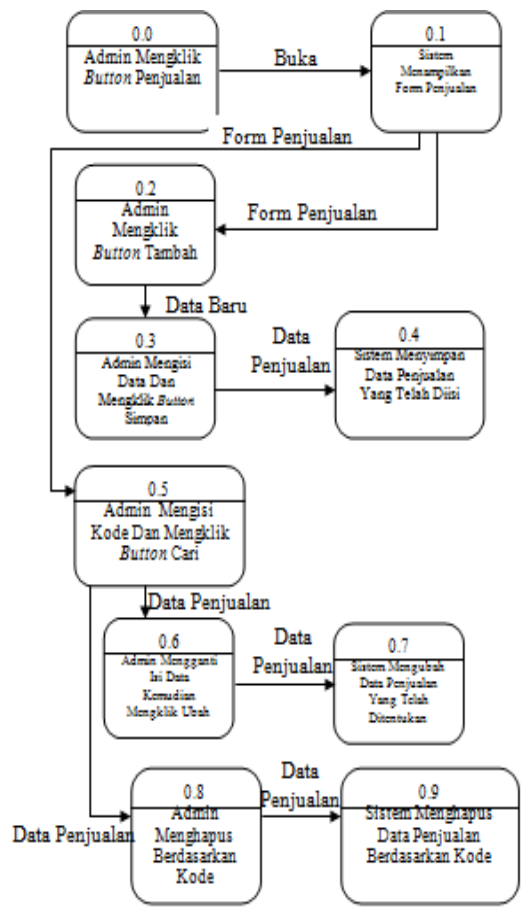

Gambar 4. Data Flow Diagram Form Pembelian (Suplier)

Gambar 5. Aplikasi Sistem Persediaan Barang.

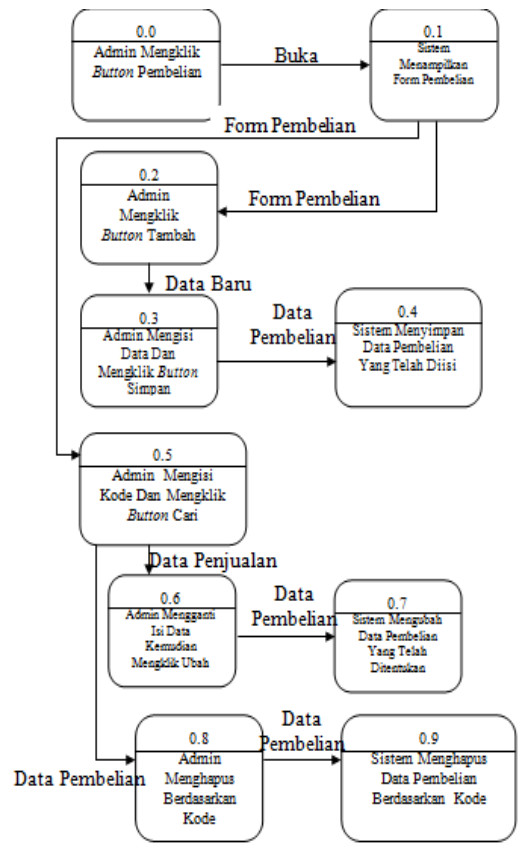

Gambar 5. Tampilan Hasil
Tampilan Hasil dari perancangan Aplikasi Sistem Informasi Persediaan Barang dapat di lihat sebagai berikut :

Tampilan Form Login

Pada Gambar 6. adalah tampilan form login dari Aplikasi Sistem Persediaan Barang.

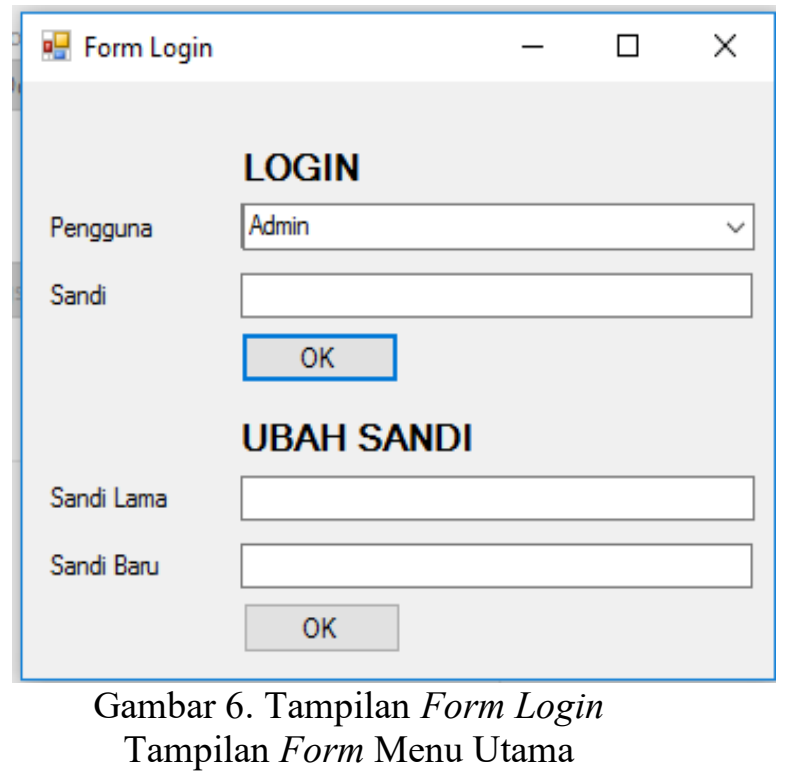

Pada Gambar 7. adalah tampilan form menu utama dari aplikasi Perancangan Aplikasi Sistem Persediaan Barang.

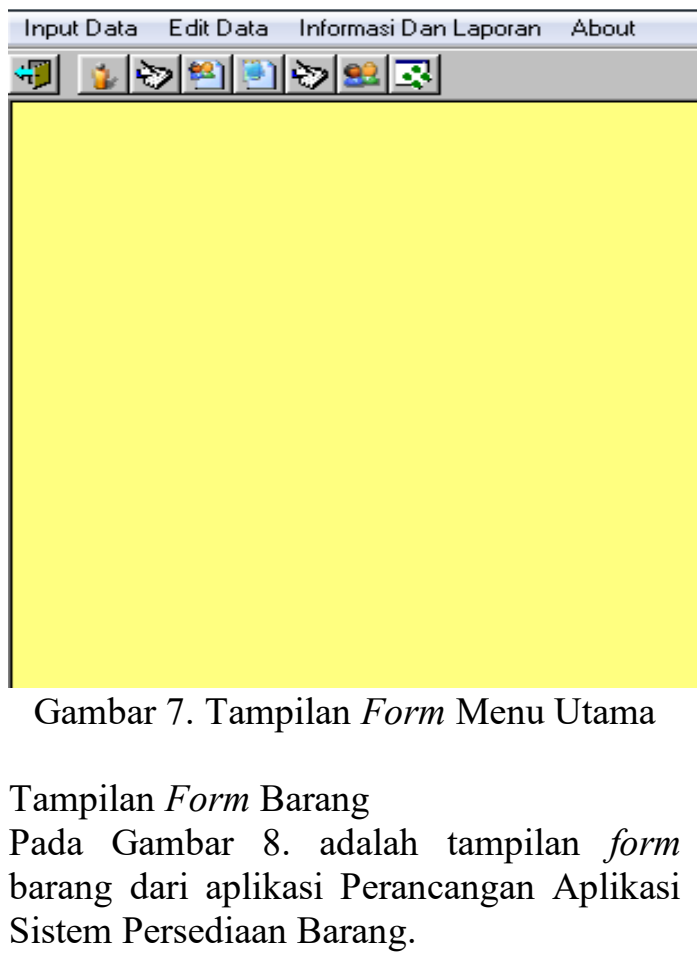




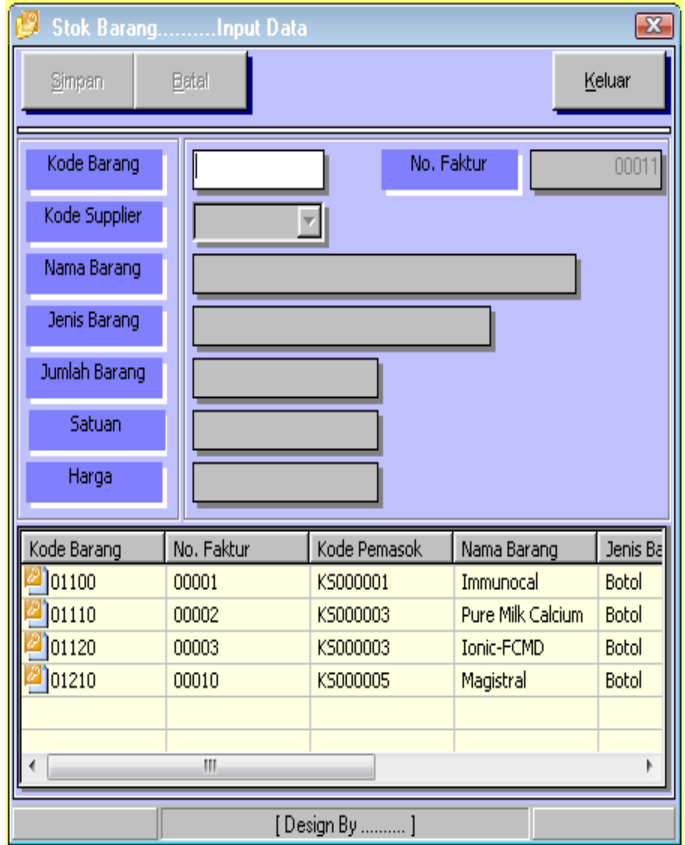

Gambar 8. Tampilan Form Barang

Tampilan Form Laporan Stok Barang

Pada Gambar 9. adalah Tampilan Form penjualan dari aplikasi Perancangan Aplikasi Sistem Persediaan Barang.

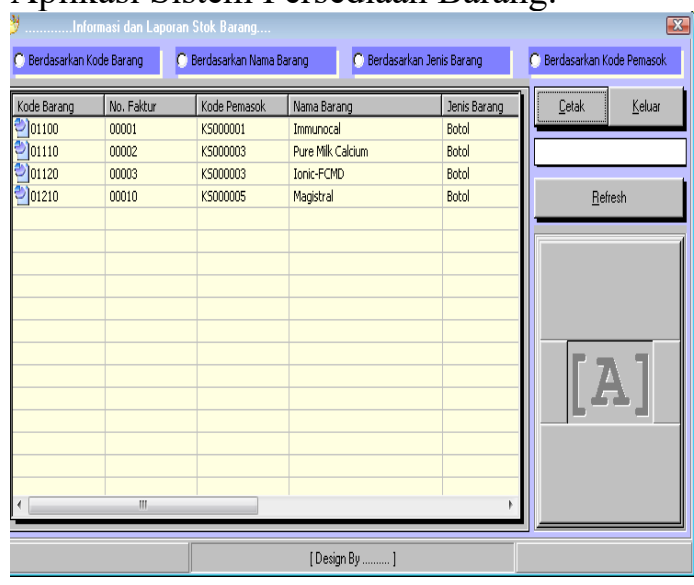

Gambar 9.Tampilan Form Laporan Stok Barang

Tampilan Form Pembelian/Suplier

Pada Gambar 10. adalah tampilan form Pembelian/Suplier dari aplikasi Perancangan Aplikasi Sistem Persediaan Barang.

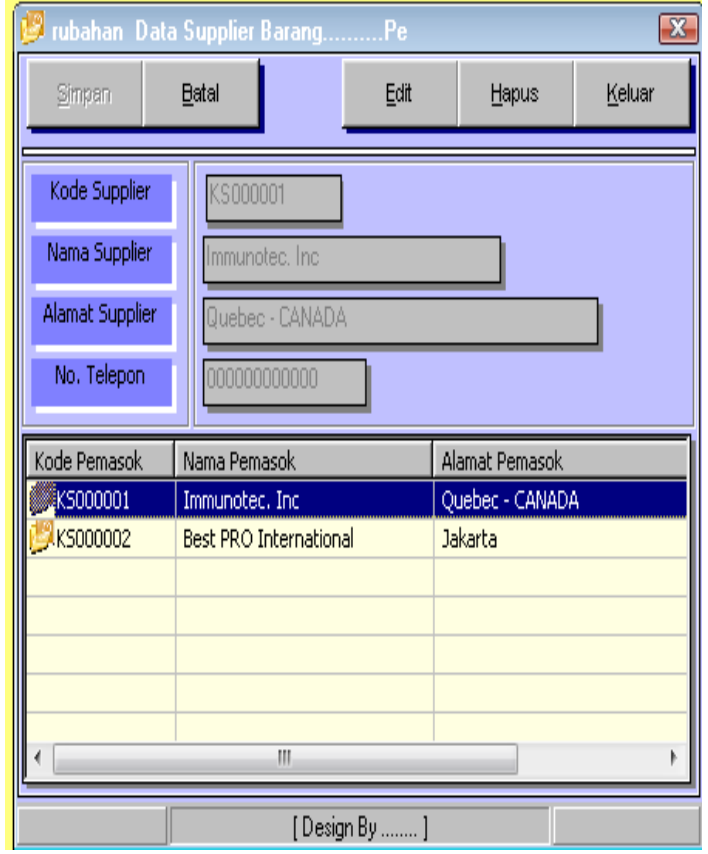

Gambar 10. Tampilan Form

Pembelian/Suplier

Tampilan Form Laporan Pembelian/Suplier Pada Gambar 11. adalah tampilan form penjualan dari aplikasi Perancangan Aplikasi Sistem Persediaan Barang.

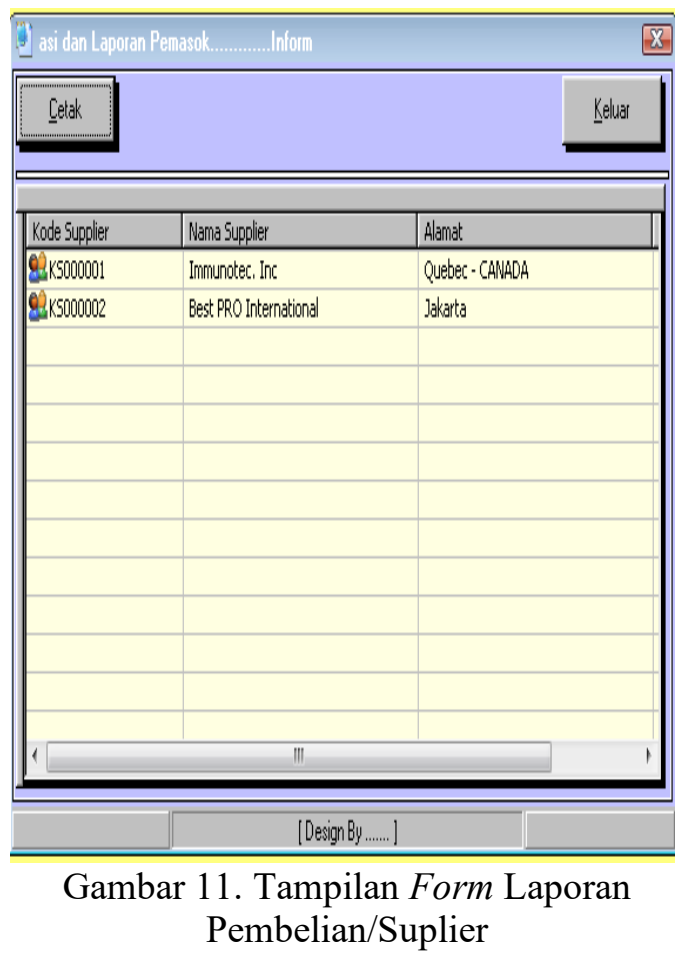

Tampilan Form Laporan Data Penjualan Pada Gambar 12. adalah tampilan form penjualan dari aplikasi Perancangan Aplikasi Sistem Persediaan Barang. 


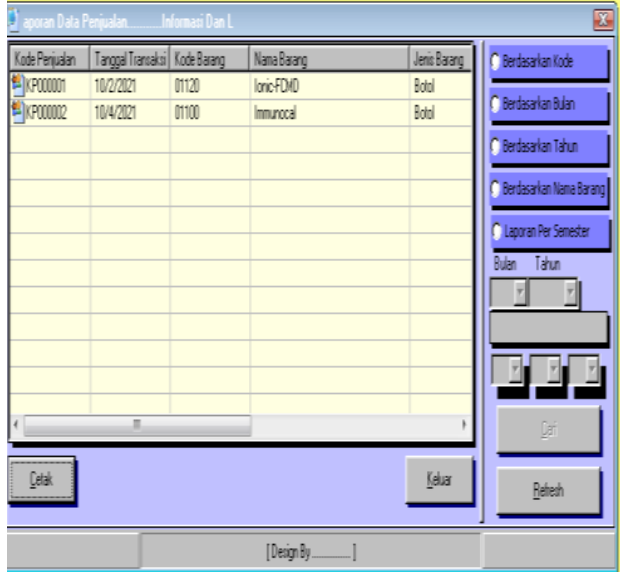

Gambar 12. Tampilan Form Pembelian/Suplier

Tampilan Form Persediaan Barang

Pada Gambar 13. adalah tampilan form Persediaan Barang dari aplikasi Perancangan Aplikasi Sistem Persediaan Barang.

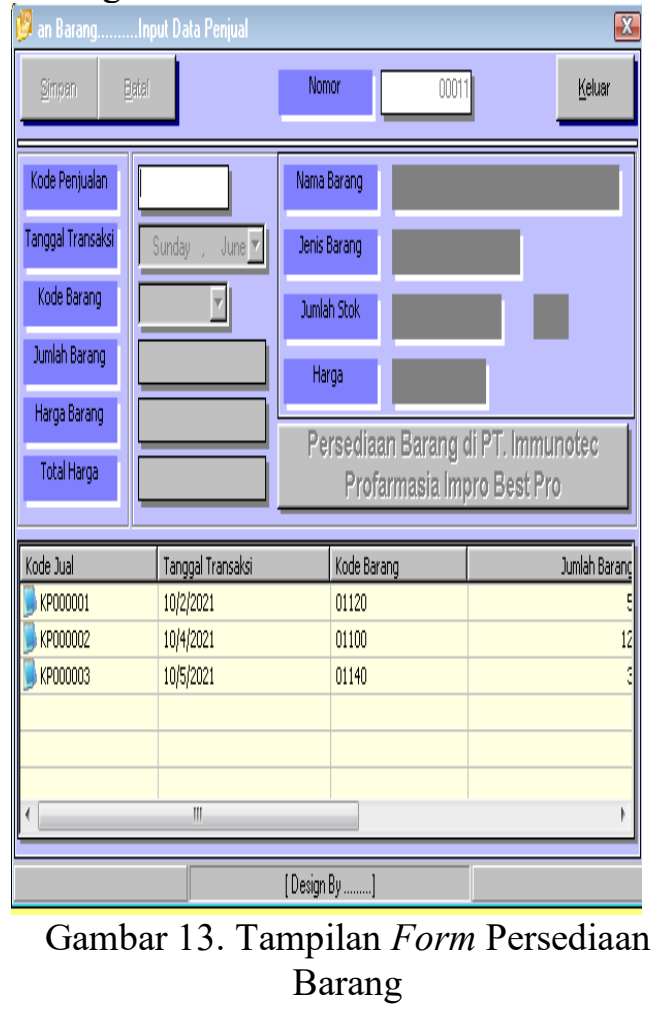

\section{KESIMPULAN}

Kegiatan Pengabdian Kepada Masyarakat yang telah dilaksanakan sararannya adalah pegawai PT. Immunotec Profarmasia Impro Best Pro dalam bentuk sosialisasi sistem informasi persediaan barang berjalan dengan lancar. Pegawai pada awalnya masih belum pernah menggunakan sistem ataupun sebuah aplikasi pemrograman sehingga terlihat masih bingung dan canggung dalam menjalankan sistem tersebut. Pada akhirnya mereka terdorong untuk mencoba dan terus berlatih menggunakan sistem itu sampai mahir. Dengan demikian sosialisasi sistem persediaan barang pada PT. Immunotec Profarmasia Impro Best Pro dapat dikatakan berhasil dengan baik.

\section{SARAN}

Berikut adalah beberapa saran yang dianggap perlu diantaranya:

Sebaiknya pelatihan seperti ini dapat dilakukan secara berkala.

Pegawai yang telah diberikan pelatihan diharapkan terus belajar dan mengkoreksi sub sub bagian apa saja yang perlu ditambahkan pada sistem persediaan barang untuk dapat diperbaiki kedepannya.

\section{UCAPAN TERIMA KASIH}

Terima kasih kami ucapkan kepada Sekolah Tinggi Teknologi Sinar Husni yang telah memfasilitasi Kegiatan Pengabdian Masyarakat. Tak lupa pula kami ucapkan kepada PT. Immunocal Profarmasia Impro Best Pro yang telah menerima kami dengan baik untuk melaksanakan Pengabdian Kepada Masyarakat sehingga sosialisasi dapat terlaksana dengan Tim dan seluruh pegawai tanpa ada kendala .

\section{REFERENSI}

[1]. Sarwindah. (2016). Sistem Informasi Manajemen Pemesanan Buku Pada Toko Buku Nuris. TEKNOSI, Vol. 02, No. 02.

[2]. Rahayu S, Nurhaeni T, Rohmah M. 2015. Sistem Persediaan Alat Tulis Kantor Sebagai Penunjang Pengambilan Keputusan Bagian Logistik Di Perguruan Tinggi Raharja. 8(2): 91-10

[3]. Maryatun, M. (2015). Pengaruh penggunaan media program microsoft powerpoint terhadap hasil belajar strategi promosi pemasaran mahasiswa semester 2 Program Studi Pendidikan Ekonomi Universitas Muhammadiyah Metro tahun ajaran 2014/2015. PROMOSI: Jurnal Program Studi Pendidikan Ekonomi, 3(1), 1-13.

[4]. Kurniawansyah, I. S. (2018). Pelatihan Peningkatan pengetahuan dan keterampilan memilih obat mata bagi tenaga kesehatan Desa Cilayung 
Kecamatan Jatinangor. Dharmakarya, 7(4), 265-268.

[5]. S. Susilawati. (2018). Perancangan Sistem Informasi Laporan Persediaan Barang Jadi PT Duta Prima Plasindo. Jurnal Sistem Sifotek ISSN: 2088 - 1762 Vol.8 No. 1.

[6]. Minarni, Susanti. 2014. Sistem Informasi Inventory Obat Pada Rumah Sakit Umum Daerah (RSUD) Padang. Jurnal Momentum. 16 (1): 103-111.

[7]. Y. Arisandy, dkk. (2017). Sistem Informasi Manajemen (Teori dan Implementasi dalam Bisnis). Pustaka Pelajar 